\title{
A Look at Person-Centered and Family-Centered Care Among Older Adults: Results from a National Survey
}

\author{
Jennifer L. Wolff, Ph.D. ${ }^{7}$ and Cynthia M. Boyd, MD, MPH. ${ }^{2}$ \\ 'Department of Health Policy and Management, Johns Hopkins Bloomberg School of Public Health, Baltimore, MD, USA; ${ }^{2}$ Division of Geriatric \\ Medicine and Gerontology, Department of Medicine, Johns Hopkins University School of Medicine, Baltimore, MD, USA.
}

\begin{abstract}
BACKGROUND: Person-centered and family-centered care represents the pinnacle of health care quality, but delivering it is challenging, as is assessing whether it has occurred. Prior studies portray older adults as passive in health decisions and burdened by care-but emphasize age-based differences or focus on vulnerable subgroups. OBJECTIVES: We aimed to examine domains of person-centered and family-centered care among older adults and whether the social context in which older adults manage their health relates to preferences for participating in health decisions and experiences with care.
\end{abstract}

DESIGN AND PARTICIPANTS: This was an observational study of a nationally representative survey of adults aged $65+$ years, conducted in concert with the 2012 National Health and Aging Trends Study (n=2040).

MAIN MEASURES: Approach to managing health (selfmanage, co-manage, delegate); preferences for making health care decisions with: (1) doctors, (2) family/close friends; and experiences with care pertaining to treatment burden were measured.

KEY RESULTS: Approximately two-thirds of older adults self-manage $(69.4 \%)$ and one-third comanage $(19.6 \%)$ or delegate $(11.0 \%)$ health care activities. The majority prefer an independent or shared role when making health decisions with doctors $(84.7 \%)$ and family/close friends (95.9\%). Nearly four in ten older adults (37.9\%) experience treatment burden-that managing health care activities are sometimes or often hard for either them or their family/close friends, that health care activities get delayed or don't get done, or that they are cumulatively too much to do. Relative to older adults who self-manage, those who delegate health care activities are more likely to prefer to share or leave health decisions to doctors (aOR=1.79 (95\% CI, 1.37-2.33) and family/close friends (aOR=3.12 (95\% CI, 2.23-4.36), and are more likely to experience treatment burden $(\mathrm{aOR}=$ 2.37 (95\% CI, 1.61-3.47).

CONCLUSIONS: Attaining person-centered and familycentered care will require strategies that respect diverse decision-making preferences, minimize treatment burden, and support the broader social context in which older adults manage their health.

Received October 22, 2014

Revised February 19, 2015

Accepted April 2, 2015

Published online May 2, 2015
KEY WORDS: decision-making; treatment burden; self-management; patient-centered care; older adults.

J Gen Intern Med 30(10): 1497-504

DOI: $10.1007 / \mathrm{s} 11606-015-3359-6$

(c) Society of General Internal Medicine 2015

$\mathrm{P}$ erson-centered and family-centered care is thought to represent the pinnacle of health care quality. ${ }^{1}$ However, delivering it is challenging, as is our ability to assess whether it has occurred. ${ }^{2}$ Attaining person-centered and family-centered care is particularly important and challenging in the care of older persons, given vast heterogeneity in health and function, treatment preferences, and individual goals. ${ }^{3,4}$ Because many older adults are heavy users of health services, they are more susceptible to treatment burden as well as harms associated with complicated therapeutic and preventive regimens. ${ }^{5-7}$ Age-related changes in sensory, cognitive, and physical function may prompt some older adults to rely on or choose to involve family members or close friends in managing their health. ${ }^{8,9}$

The existing literature generally indicates that older adults prefer a passive role in health care decision-making ${ }^{10-12}$ and portrays older adults as burdened by care. ${ }^{13,14}$ However, prior studies have typically emphasized age-related differences, ${ }^{10,11}$ or focused on targeted subgroups of older adults with low-literacy, poor health, or specific conditions. ${ }^{12-16}$ Understanding what people view to be important and their experience of care is foundational in the measurement of person-centered and family-centered care. ${ }^{2}$ Therefore, we designed a study to understand older adults' preferences for participating in health care decision-making and their experiences with care as measured by aspects of treatment burden associated with managing health. We address existing gaps in the measurement of person-centered and family-centered care by drawing on a nationally representative, population-based data source to examine issues that are meaningful to those receiving care, focusing on the entire care experience as opposed to a single decision or point in time. ${ }^{2}$ We sought to understand if older adults' perspectives vary with respect to whether they manage their health independently or with the involvement of family or close friends. 


\section{METHODS}

\section{Data Sources and Study Sample}

This study draws on the 2012 National Health and Aging Trends Study (NHATS), a population-based survey of health and disability trends and trajectories among Medicare beneficiaries aged 65 years and older. NHATS fields annual inperson interviews with study participants or a proxy if the participant is unable to respond. The NHATS study design and procedures have been described previously. ${ }^{17,18}$ The sample for this study includes a random sample of 2040 participants who responded to a supplemental module fielded in 2012 and who were living in the community or a residential care facility. Wave 2 response rates were $84.5 \%$ for community-dwelling and $94.1 \%$ for residential care participants, respectively. ${ }^{19}$ Participants living in nursing homes were excluded. With sample weights, participants represent approximately 33.4 million Medicare beneficiaries ages 65 and older. As the data used in this analysis are publicly available with no unique identifiers, our study was exempt from Institutional Review Board review.

\section{Study Outcomes}

Study outcomes reflect domains of person-centered and family-centered care that relate to the social context in which health care activities are performed with family/close friends, preferences for participating in health care decisions, and the experience of care (See Box). Because older adults' preferences for health care decision-making and perspectives on managing their health in part reflect how activities are performed, we first examine how older adults manage health care activities using three categories: "self-manage", "co-manage" with family members or close friends, and "delegate" to family members or close friends. To assess preferences for health care decision-making, we devised questions with attention to existing measures and recent conceptual work indicating the importance of doctors, as well as family and close friends, as elements of informed decision-making. ${ }^{10,20,21}$ We separately examined older adults' preferences for participating in health care decisions with doctors and family and close friends using the following categories: "making decisions independently, with or without advice", "share decisions" and "leave decisions up to them." Finally, we developed questions to assess older adults' perspectives on their experiences managing their health, drawing on prior work to articulate disease-specific treatment burden. ${ }^{6,7,22-24}$ We constructed a summary measure that identified participants who reported that one or more of four individual experiences relating to treatment burden occur "sometimes" or "often."

\section{Covariates}

We examine older adults' age, gender, educational attainment, self-rated health, numbers of chronic medical conditions, selfreported hospitalization in the prior year, and sensory

\section{Box 1.}

How Participants Manage Health Care Activities:

Participants were read the statement: "People today are asked by their doctors and other health care providers to do many things to stay healthy or treat health problems-for example, manage medicines, get tests and lab work done, watch weight and blood pressure, or have yearly exams." Participants were asked: "How do you usually handle these things?"

Response categories included:

- Mostly independently (subsequently referred to as "self-manage"),

- Together with family members or close friends (subsequently referred to as "co-manage"),

- Mostly managed by others, ${ }^{*}$

- It varied.*

*As these response categories were endorsed by fewer participants with similar sociodemographic and health characteristics, they were combined for reporting purposes. For simplicity we refer to this combined group as "delegate."

\section{Preferences for Health Care Decision-Making:}

Participants were read the statement: "People today are faced with many decisions about their health care-for example whether to start or change a medicine. We want to know how you prefer to have doctors and family or close friends help with decisions."

Participants were separately asked about both doctors and family and close Friends as follows:

Doctors: "Thinking about your doctors, do you prefer to..."

Family and Close Friends: "Thinking about your family and close friends, do you prefer to..."

Response categories included:

- Make decisions without much advice,**

- Get their advice and then make decisions, ${ }^{* *}$

- Make decisions together (subsequently referred to as "share decisions")

- Leave decisions up to them.

**The first two response categories are combined, which we subse quently refer to as "making decisions independently, with or without advice."

\section{Experiences that Pertain to Treatment Burden}

Participants were asked to reflect on the things they are asked to do to stay healthy or treat health problems as listed above (managing medicines, getting tests and lab work done, watching weight and blood pressure, or having yearly exams). They were then asked the following four questions:

- "How often are these things difficult for you to do?"

- "How often are these things difficult for your family or close friends to handle?"

- "How often do these things that you do to stay healthy or treat health problems get delayed or not get done?"

- "How often do you feel that doctors or other providers ask you to do too much?"

Response categories for questions included: "never", "rarely", "sometimes", and "often."

We constructed a summary measure to identify participants who reported that one or more of the four experiences that pertain to treatment burden occur "sometimes" or "often."

impairment. Depressive symptoms were measured using established cut-points of the PHQ-2. ${ }^{25}$ Cognitive impairment was examined using a composite measure from self-reported doctor diagnosis of Alzheimer's disease or dementia, the AD8 dementia screening interview that was administered to proxy respondents, ${ }^{26}$ and cognitive tests to evaluate participant's memory, orientation, and executive function. ${ }^{27}$

\section{Analytic Approach}

We described participants' sociodemographic and health characteristics in relation to how they manage health care activities. We then examined older adults' health care decisionmaking preferences and experience of treatment burden, stratified by how they manage health care activities. Finally, we constructed simple and multivariate logistic regression models 
to investigate the strength and magnitude of characteristics of older adults in relation to decision-making preferences and treatment burden. Sensitivity analyses were conducted using the subsample of participants who self-reported survey responses (94.1\% of weighted participants; data available on request). Proxy responses were more common among participants who co-managed ( $7.6 \%)$ or delegated $(27.4 \%)$ health care activities than among participants who self-managed $(1.1 \%)$. However, as sensitivity analyses yielded comparable estimates and confidence intervals, results for the full sample (including proxy respondents) are reported. All analyses were conducted in SAS 9.3 using survey sampling weights and statements to account for the complex sampling strategy of NHATS.

\section{RESULTS}

An estimated 23.2 million (69.4\%) older adults self-manage their health, 6.6 million (19.6\%) co-manage their health, and 3.7 million $(11.0 \%)$ delegate health care activities to family or close friends (Table 1). How older adults manage health care activities varies widely by sociodemographic and health characteristics. With greater age, lower educational attainment, and worse self-rated health, older adults are incrementally less likely to self-manage and more likely to co-manage or delegate health care activities. For example, relative to those who self-manage their health, older adults who co-manage or delegate health care activities are older $(73.7,76.8$, and 78.7 years respectively), more likely to rate their health as fair or poor $(17.4 \%, 29.5 \%$, and $37.0 \%)$ and to have cognitive impairment $(2.4 \%, 13.0 \%$, and $31.7 \%)$.

Older adults' decision-making preferences vary widely with respect to how they manage health care activities (Table 2). Among older adults who self-manage their health, most prefer to make health care decisions independently with or without their doctor's advice $(50.6 \%)$ or share decisions with their doctors $(36.5 \%)$, and fewer $(12.5 \%)$ prefer to leave decisions up to doctors. In contrast, among older adults who delegate health care activities to family or close friends, decisionmaking preferences with doctors are relatively balanced with respect to making decisions independently with or without their doctor's advice $(30.4 \%)$, sharing decisions $(37.7 \%)$, or leaving decisions to their doctor (30.3\%).

Approximately one-third (31.9\%) of older adults prefer to share or leave health care decisions to family members and close friends. Among older adults who self-manage their health, most prefer to make health care decisions independently with or without advice from family and close friends (77.2\%), and fewer prefer to share $(21.4 \%)$ or leave decisions to family and close friends (1.3\%). Among older adults who co-manage their health, about half prefer to make decisions independently $(47.7 \%)$ or share decisions $(49.1 \%)$, few $(2.9 \%)$ prefer to leave decisions to family and close friends. Older adults who delegate management of health care
Table 1 Characteristics of Community-Dwelling Older Adults by Management of Health Care Activities

\begin{tabular}{|c|c|c|c|}
\hline \multirow[b]{3}{*}{$\begin{array}{l}\text { Population estimate } \\
\text { (row \%)** }\end{array}$} & \multicolumn{3}{|c|}{$\begin{array}{l}\text { Manage Health Care Activities } \\
\text { (Column \%) }\end{array}$} \\
\hline & \multirow{2}{*}{$\begin{array}{l}\begin{array}{l}\text { Self- } \\
\text { Manage }\end{array} \\
\mathbf{2 3 , 2 0 0 , 0 0 0} \\
(\mathbf{6 9 . 4 \% )}\end{array}$} & \multirow{2}{*}{$\begin{array}{l}\begin{array}{l}\text { Co- } \\
\text { Manage }\end{array} \\
\mathbf{6 , 6 0 0 , 0 0 0} \\
(19.6 \%)\end{array}$} & \multirow{2}{*}{$\begin{array}{l}\text { Delegate } \\
3,700,000 \\
(11.0 \%)\end{array}$} \\
\hline & & & \\
\hline Mean age & 73.7 & 76.8 & 78.7 \\
\hline \multirow{2}{*}{\multicolumn{4}{|c|}{ Educational Attainment ${ }^{\dagger}$}} \\
\hline & & & \\
\hline Less than High School & $17.5 \%$ & $32.8 \%$ & $34.2 \%$ \\
\hline High School & & $26.9 \%$ & $25.3 \%$ \\
\hline Some College & $26.9 \%$ & $17.7 \%$ & $21.6 \%$ \\
\hline College or Beyond & $28.8 \%$ & $22.5 \%$ & $18.9 \%$ \\
\hline \multicolumn{4}{|l|}{ Self-Rated Health ${ }^{\dagger}$} \\
\hline Excellent or very good & $50.5 \%$ & $35.5 \%$ & $27.8 \%$ \\
\hline Good & $32.1 \%$ & $34.9 \%$ & $35.2 \%$ \\
\hline Fair or poor & $17.4 \%$ & $29.5 \%$ & $37.0 \%$ \\
\hline Depressive Symptoms ${ }^{\dagger}$ & $9.3 \%$ & $16.5 \%$ & $26.9 \%$ \\
\hline \multicolumn{4}{|l|}{ Cognitive Impairment } \\
\hline No evidence & $88.4 \%$ & $73.0 \%$ & $56.1 \%$ \\
\hline Indeterminate & $9.2 \%$ & $14.0 \%$ & $12.2 \%$ \\
\hline Probable & $2.4 \%$ & $13.0 \%$ & $31.7 \%$ \\
\hline Significant Sensory & $3.7 \%$ & $10.4 \%$ & $18.4 \%$ \\
\hline Impairment & & & \\
\hline \multicolumn{4}{|c|}{ Numbers of Chronic Medical Conditions ${ }^{\S}$} \\
\hline None & $11.0 \%$ & $9.7 \%$ & $7.8 \%$ \\
\hline One & $21.5 \%$ & $18.8 \%$ & $17.1 \%$ \\
\hline Two & $31.9 \%$ & $25.7 \%$ & $31.3 \%$ \\
\hline Three or more & $35.5 \%$ & $45.9 \%$ & $43.9 \%$ \\
\hline Hospitalized in Prior Year ${ }^{\dagger}$ & $20.1 \%$ & $28.2 \%$ & $34.1 \%$ \\
\hline
\end{tabular}

Source: National Health and Aging Trends Study, 2012

* Data are weighted to reflect community-dwelling Medicare beneficiaries ages 65 years or older using the 2011 sample frame ( $n=6154)$; individuals living in nursing facilities $(n=418)$ or who died $(n=503)$ were excluded

${ }^{*}<1 \%$ of observations with responses of "don't know", "refused", or "not ascertained"; categorized as less than high school education, "poor" self-rated health, absence of depressive symptoms, and not hospitalized in prior year

${ }^{7}$ Respondent report of being deaf or unable to hear well enough to use the telephone or carry on a conversation in a quiet room with a hearing aid, or being blind or unable to see well enough to read newspaper print with vision aids or glasses.

${ }^{\S}$ Chronic medical conditions refer to self-reported physician diagnosis of heart attack, heart disease, high blood pressure, arthritis, osteoporosis, diabetes, lung disease, stroke, cancer, and hip fracture

activities express a greater preference for involving family and close friends in health care decisions; less than half prefer to make decisions independently ( $44.8 \%$ ), with the remainder preferring to share $(32.6 \%)$ or leave health care decisions to family and close friends $(21.7 \%)$.

One-fourth $(24.1 \%)$ of older adults report the things they do to stay healthy are "sometimes or often difficult" for them (bottom panel of Table 2). Older adults who co-manage or delegate health care activities to others report that managing their health is sometimes or often hard for family or close friends ( $20.1 \%$ and $28.0 \%$, respectively). About one in five older adults report that health care activities sometimes or often get delayed or do not get done (range: 20.1-22.9\%). Fewer older adults report that doctors or other providers asked them to "do too much" (range: $12.1 \%$ to $13.1 \%$ ). These reports varied little on the basis of how health care activities 
Table 2 Older Adults' Preferences for Participating in Health Care Decisions and Experience of Treatment Burden

\begin{tabular}{|c|c|c|c|c|}
\hline \multirow[b]{2}{*}{ Older Adults' Preferences for Health Care Decision-Making } & \multirow[b]{2}{*}{ Total } & \multicolumn{3}{|c|}{ Manage Health Care Activities (Column \%) } \\
\hline & & Self-Manage & Co-Manage & Delegate \\
\hline \multicolumn{5}{|l|}{ With Doctors } \\
\hline Make decisions independently with or without doctor advice & $47.3 \%$ & $50.6 \%$ & $45.0 \%$ & $30.4 \%$ \\
\hline Share decisions & $37.4 \%$ & $36.5 \%$ & $40.6 \%$ & $37.7 \%$ \\
\hline Leave decisions up to them & $14.8 \%$ & $12.5 \%$ & $14.3 \%$ & $30.3 \%$ \\
\hline \multicolumn{5}{|l|}{ With Family and Friends } \\
\hline Make decisions independently with or without family/friend advice & $67.8 \%$ & $77.2 \%$ & $47.7 \%$ & $44.8 \%$ \\
\hline Share decisions & $28.1 \%$ & $21.4 \%$ & $49.1 \%$ & $32.6 \%$ \\
\hline Leave decisions up to them & $3.8 \%$ & $1.3 \%$ & $2.9 \%$ & $21.7 \%$ \\
\hline \multicolumn{5}{|l|}{ Older Adults' Experience of Treatment Burden } \\
\hline \multicolumn{5}{|l|}{ "The things that you are asked to do to stay healthy are 'sometimes or often...", } \\
\hline - Hard for you (the participant)? ${ }^{\dagger}$ & $24.1 \%$ & $21.9 \%$ & $30.8 \%$ & $25.4 \%$ \\
\hline - Hard for family or close friends? & $7.0 \%$ & $0.0 \%$ & $20.1 \%$ & $28.0 \%$ \\
\hline - Get delayed or not get done? & $22.1 \%$ & $22.6 \%$ & $20.1 \%$ & $22.9 \%$ \\
\hline - How often do you feel that doctors/other providers ask you to do too much? & $12.4 \%$ & $12.1 \%$ & $12.9 \%$ & $13.1 \%$ \\
\hline Treatment Burden, defined as one or more of the above & $37.9 \%$ & $34.3 \%$ & $41.7 \%$ & $54.0 \%$ \\
\hline
\end{tabular}

Source: National Health and Aging Trends Study, 2012

*Data are weighted to represent 33.4 million community-dwelling Medicare beneficiaries ages 65 years or older

${ }^{*}$ Individuals who reported that family or close friends manage health care activities were not asked this question. The percentage listed in the "delegate" column reflect responses of individuals who reported that how they manage their health care activities "varies" (in the numerator) in relation to the combined group of those who reported that family or close friends manage health care activities or that it "varies" (in the denominator; see Box for further clarification). Of those asked the question, $42.1 \%$ reported the things they are asked to do to stay health are "sometimes or often" hard for them

were managed. Nearly four in ten older adults (37.9\%) experience some degree of treatment burden on the basis of reporting one or more of the four experiences sometimes or often. Treatment burden was experienced more often among those who co-manage $(41.7 \%)$ or delegate $(54.0 \%)$ health care activities than those who self-manage (34.3\%).

Table 3 Preferences for Participating in Health Care Decisions with Doctors and Family/Close Friends: Multivariate Regression Results

\begin{tabular}{|c|c|c|c|c|c|c|c|c|}
\hline & \multicolumn{8}{|c|}{ Prefer to Share or Leave Health Care Decisions Up To: } \\
\hline & \multicolumn{4}{|l|}{ Doctor } & \multicolumn{4}{|c|}{ Family or Friends } \\
\hline & \multicolumn{2}{|c|}{ Unadjusted } & \multicolumn{2}{|c|}{ Adjusted * } & \multicolumn{2}{|c|}{ Unadjusted } & \multicolumn{2}{|c|}{ Adjusted * } \\
\hline & OR & $(95 \% \mathrm{CI})$ & aOR & $(95 \% \mathrm{CI})$ & OR & $(95 \% \mathrm{CI})$ & aOR & $(95 \% \mathrm{CI})$ \\
\hline Age & 1.01 & $(1.00,1.02)$ & 1.00 & $(0.98,1.01)$ & 1.03 & $(1.01,1.04)$ & 1.00 & $(0.99,1.02)$ \\
\hline Male Gender & 1.30 & $(1.06,1.59)$ & 1.38 & $(1.13,1.67)$ & 1.20 & $(0.96,1.49)$ & 1.18 & $(0.91,1.52)$ \\
\hline \multicolumn{9}{|l|}{ Education } \\
\hline College or beyond & \multicolumn{2}{|c|}{ Reference Group } & \multicolumn{2}{|c|}{ Reference Group } & \multicolumn{2}{|c|}{ Reference Group } & \multicolumn{2}{|c|}{ Reference Group } \\
\hline Some college & 0.89 & $(0.64,1.24)$ & 0.88 & $(0.63,1.24)$ & 1.20 & $(0.87,1.67)$ & 1.24 & $(0.88,1.76)$ \\
\hline High school & 1.17 & $(0.87,1.58)$ & 1.14 & $(0.86,1.52)$ & 1.25 & $(0.94,1.67)$ & 1.16 & $(0.85,1.59)$ \\
\hline Less than high school & 1.24 & $(0.94,1.64)$ & 1.02 & $(0.76,1.38)$ & 1.83 & $(1.40,2.38)$ & 1.30 & $(1.01,1.67)$ \\
\hline \multicolumn{9}{|l|}{ Self-Rated Health } \\
\hline Excellent or very good & \multicolumn{2}{|c|}{ Reference Group } & \multicolumn{2}{|c|}{ Reference Group } & \multicolumn{2}{|c|}{ Reference Group } & \multicolumn{2}{|c|}{ Reference Group } \\
\hline Good & 1.38 & $(1.13,1.69)$ & 1.19 & $(0.94,1.53)$ & 1.03 & $(0.81,1.31)$ & 0.77 & $(0.57,1.05)$ \\
\hline Fair or poor & 1.33 & $(1.04,1.70)$ & 1.04 & $(0.76,1.41)$ & 1.62 & $(1.24,2.12)$ & 0.97 & $(0.71,1.31)$ \\
\hline Depressive Symptoms & 1.15 & $(0.87,1.53)$ & 0.92 & $(0.70,1.22)$ & 1.66 & $(1.22,2.27)$ & 1.17 & $(0.82,1.65)$ \\
\hline \multicolumn{9}{|l|}{ Cognitive Impairment } \\
\hline No evidence & \multicolumn{2}{|c|}{ Reference Group } & \multicolumn{2}{|c|}{ Reference Group } & \multicolumn{2}{|c|}{ Reference Group } & \multicolumn{2}{|c|}{ Reference Group } \\
\hline Possible & 1.13 & $(0.81,1.58)$ & 1.01 & $(0.71,1.45)$ & 1.51 & $(1.07,2.14)$ & 1.21 & $(0.84,1.76)$ \\
\hline Probable & 2.06 & $(1.49,2.83)$ & 1.54 & $(1.11,2.14)$ & 3.54 & $(2.61,4.79)$ & 1.87 & $(1.29,2.72)$ \\
\hline Significant Sensory Impairment & 1.81 & $(1.27,2.59)$ & 1.37 & $(0.96,1.95)$ & 2.14 & $(1.50,3.05)$ & 1.13 & $(0.75,1.71)$ \\
\hline \multicolumn{9}{|l|}{ Chronic Medical Conditions } \\
\hline None & \multicolumn{2}{|c|}{ Reference Group } & \multicolumn{2}{|c|}{ Reference Group } & \multicolumn{2}{|c|}{ Reference Group } & \multicolumn{2}{|c|}{ Reference Group } \\
\hline One & 0.98 & $(0.67,1.44)$ & 1.00 & $(0.68,1.45)$ & 1.12 & $(0.76,1.66)$ & 1.15 & $(0.72,1.84)$ \\
\hline Two & 1.61 & $(1.07,2.40)$ & 1.61 & $(1.08,2.39)$ & 1.55 & $(1.12,2.16)$ & 1.60 & $(1.07,2.40)$ \\
\hline Three or More & 1.54 & $(1.10,2.16)$ & 1.47 & $(1.04,2.06)$ & 1.61 & $(1.10,2.34)$ & 1.45 & $(0.91,2.33)$ \\
\hline Hospitalized in Prior Year & 1.23 & $(0.96,1.56)$ & 1.07 & $(0.83,1.39)$ & 1.23 & $(0.96,1.57)$ & 0.98 & $(0.72,1.33)$ \\
\hline \multicolumn{9}{|l|}{ Manage Health Care Activities } \\
\hline Self-manage & \multicolumn{2}{|c|}{ Reference Group } & Refer & Group & Refe & Group & Refer & Group \\
\hline Co-manage & 1.26 & $(0.96,1.66)$ & 1.12 & $(0.83,1.51)$ & 3.70 & $(2.76,4.97)$ & 3.33 & $(2.44,4.55)$ \\
\hline Delegate & 2.20 & $(1.70,2.86)$ & 1.79 & $(1.37,2.33)$ & 4.07 & $(3.01,5.51)$ & 3.12 & $(2.23,4.36)$ \\
\hline
\end{tabular}

Source: National Health and Aging Trends Study, 2012

Bold entries are significant to $P<0.05$

*Adjusted for age, gender, education, self-rated health, depressive symptoms, cognitive impairment, sensory impairment, hospitalization in prior year, and approach to managing health care activities 
Table 4 Older Adults' Perspectives on Experience of Treatment Burden: Multivariate Regression Results

\begin{tabular}{|c|c|c|c|c|}
\hline & \multicolumn{4}{|l|}{ Treatment Burden } \\
\hline & \multicolumn{2}{|l|}{ Unadjusted } & \multicolumn{2}{|c|}{ Adjusted * } \\
\hline & OR & $(95 \% \mathrm{CI})$ & aOR & $(95 \%$ CI) \\
\hline Age & 0.99 & $(0.98,1.01)$ & 0.97 & $(0.96,0.99)$ \\
\hline Male Gender & 0.95 & $(0.78,1.17)$ & 0.91 & $(0.73,1.15)$ \\
\hline \multicolumn{5}{|l|}{ Education } \\
\hline College or beyond & Reference Group & & Refer & \\
\hline Some college & 1.51 & $(1.14,2.00)$ & 1.32 & $(0.99,1.76)$ \\
\hline High school & 1.28 & $(0.98,1.66)$ & 1.09 & $(0.83,1.44)$ \\
\hline Less than high school & 1.88 & $(1.47,2.39)$ & 1.36 & $(1.01,1.83)$ \\
\hline \multicolumn{5}{|l|}{ Self-Rated Health } \\
\hline Excellent or very good & Reference Group & & Refer & \\
\hline Good & 1.53 & $(1.23,1.91)$ & 1.41 & $(1.09,1.82)$ \\
\hline Fair or poor & 2.48 & $(1.95,3.15)$ & 2.01 & $(1.54,2.64)$ \\
\hline Depressive Symptoms & 2.26 & $(1.78,2.87)$ & 1.70 & $(1.25,2.32)$ \\
\hline \multicolumn{5}{|l|}{ Cognitive Impairment } \\
\hline No evidence & Reference Group & Reference Group & & \\
\hline Possible & 1.16 & $(0.83,1.63)$ & 0.99 & $(0.69,1.42)$ \\
\hline Probable & 1.46 & $(1.08,1.97)$ & 1.10 & $(0.74,1.64)$ \\
\hline Significant Sensory Impairment & 1.61 & $(1.13,2.31)$ & 1.25 & $(0.80,1.96)$ \\
\hline \multicolumn{5}{|c|}{ Numbers of Chronic Medical Conditions } \\
\hline None & Reference Group & Reference Group & & \\
\hline One & 1.04 & $(0.66,1.66)$ & 1.06 & $(0.66,1.71)$ \\
\hline Two & 1.44 & $(0.94,2.23)$ & 1.31 & $(0.79,2.14)$ \\
\hline Three or More & 1.83 & $(1.24,2.71)$ & 1.41 & $(0.88,2.25)$ \\
\hline Hospitalized in Prior Year & 1.14 & $(0.91,1.43)$ & 0.85 & $(0.66,1.10)$ \\
\hline \multicolumn{5}{|l|}{ Manage Health Care Activities } \\
\hline Self-manage & Reference Group & Reference Group & & \\
\hline Co-manage & 1.37 & $(1.05,1.79)$ & 1.31 & $(0.96,1.79)$ \\
\hline Delegate & 2.26 & $(1.73,2.94)$ & 2.37 & $(1.61,3.47)$ \\
\hline
\end{tabular}

Source: National Health and Aging Trends Study, 2012

Bold entries are significant to $P<0.05$

*Adjusted for age, gender, education, self-rated health, depressive symptoms, cognitive impairment, sensory impairment, numbers of chronic medical conditions, hospitalization in prior year, and approach to managing health care activities

We constructed simple and multivariate regression models to determine whether older adults' sociodemographic and health characteristics and how they manage their health relates to preferences for participating in health care decisions with doctors (Table 3; left panel) and family and close friends (Table 3; right panel). Relative to women, men were more likely to prefer to share or leave decisions to doctors $(\mathrm{aOR}=1.30$; $95 \%$ CI: 1.07 1.57 ), as were older adults with (versus without) cognitive impairment $(\mathrm{aOR}=1.53$; $95 \% \mathrm{CI}: 1.09-2.14)$ and two $(\mathrm{aOR}=1.61$; $95 \%$ CI: $1.08,2.39$ ) or three or more (versus no) chronic medical conditions (aOR=1.47; $95 \% \mathrm{CI}$ : 1.04-2.06). In comparison with older adults who self-managed their health, those who delegated health care activities to family members and friends were significantly more likely to prefer to share or leave health care decisions to doctors ( $\mathrm{aOR}=1.79 ; 95 \%$ CI 1.37-2.33).

Older adults with less than high school education (versus college or more) $\mathrm{aOR}=1.30$; $95 \% \mathrm{CI}$ : 1.01-1.67) and cognitive impairment (aOR=1.87; $95 \%$ CI: 1.29-2.72) were significantly more likely to prefer to share or leave health care decisions to family and close friends. In comparison with older adults who self-managed their health, those who co-managed or delegated health care activities to family members and friends were more than three times as likely to prefer to share or leave health care decisions to family or close friends ( $\mathrm{aOR}=3.33 ; 95 \%$ CI: 2.44 4.55 and aOR 3.12; $95 \%$ CI: 2.23-4.36, respectively).
Markers of poor health and health literacy were strongly associated with the experience of treatment burden (Table 4). In comparison to older adults who rated their health as excellent or very good, those in fair or poor health were twice as likely $(\mathrm{aOR}=2.01 ; 95 \% \mathrm{CI}: 1.54-2.64)$ and those in good health were 1.41 times more likely $(\mathrm{aOR}=1.41 ; 95 \% \mathrm{CI}$ : $1.09-1.82)$ to experience treatment burden. Individuals with (versus without) depressive symptoms (95\% CI: 1.25-2.32) and less than high school education (versus college or more) $(\mathrm{aOR}=1.36 ; 95 \% \mathrm{CI}: 1.01-1.83)$ were significantly more likely to report treatment burden. Older adults who delegate health care activities were more than twice as likely to report treatment burden relative to those who self-manage their health $(\mathrm{aOR}=2.37$; $95 \% \mathrm{CI}: 1.61-3.47)$.

\section{DISCUSSION}

Drawing on newly available data from a nationally representative survey, we find that a majority of older adults self-manage their health $(69.4 \%)$ and prefer an independent or shared role when making health care decisions with both doctors $(84.7 \%)$ and family/close friends $(95.9 \%)$. However, relative to older adults who self-manage their health, those who co-manage or 
delegate health care activities desire a less active role in health care decision-making. Among older adults who delegate health care activities to family or close friends, $30.3 \%$ prefer to leave health care decisions to their doctor and $21.7 \%$ prefer to leave health care decisions to family and close friends. Some study findings give reason for pause. We found that nearly four in ten older adults report that managing health care activities is sometimes or often hard for them, sometimes or often hard for their family members, that health care activities get delayed or don't get done, or that these activities are cumulatively too much to do. Thus, findings suggest that the experience of treatment burden imposed by our current health care system is far from rare. Collectively, study findings provide important insight regarding the meaning of person-centered and family-centered care, and raise clinical practice, quality measurement, and policy implications.

Our finding that the overwhelming majority of older adults prefer to participate actively in health care decisions is notable and diverges from a literature that has generally portrayed older adults as passive and disengaged in health care decision-making. Prior studies have emphasized age-based differences in decision-making preferences by comparing older adults with working-age adults, ${ }^{10,11}$ or by focusing on targeted subgroups of older adults with low-literacy or poor health. ${ }^{12,15}$ Our results corroborate findings from a recent systematic review indicating a trend toward greater patient preferences for active participation in health care decision-making, ${ }^{28}$ and qualitative studies reporting substantial diversity in older adults' decisionmaking preferences. ${ }^{15,29,30}$

This study provides new insight regarding the context in which many older adults manage their health, engage in health care decision-making, and experience health care demands. Emerging evidence that patients commonly elect to involve family or close friends in routine or difficult treatment decisions $\mathrm{s}^{20,31-33}$ has prompted elaborations of shared decision-making models that explicitly include family. ${ }^{20,21}$ These are the first national data to specifically elicit decision-making preferences of older adults that extend beyond their doctor, and we find that a substantial one-third of older adults prefer to share or leave health care decisions to family members and close friends. Equally important, however, is that nearly half of older adults who co-manage or delegate management of health activities prefer to make health care decisions independently. The heterogeneity of older adults' decision-making preferences suggests that attaining person-centered and family-centered care will require a greater appreciation of the diversity of individual preferences for active engagement in care. Findings support recommendations for proactive and systematic elicitation of individuals' wishes regarding the inclusion of family and close friends who may be present during a visit or at the bedside, in medical decision-making. ${ }^{34,35}$

Poor health and delegation of health care activities to others were most strongly associated with aspects of treatment burden related to managing health activities. The clinical relevance of treatment burden has been established for consequential outcomes such as adherence to prescribed treatments, quality of life, and health services utilization..$^{13,22,36-38}$ That aspects of burden associated with managing health was more commonly experienced by persons in worse health underscores the practical importance of incorporating individual perspectives and preferences in prioritization of possible treatment and preventive regimens by balancing evidence of clinical benefit with minimizing burdens. ${ }^{39-41}$ Current delivery and reimbursement structures fail to support providers' ability to comprehensively deliberate with patients about the risks and benefits of alternative treatment options and preventive strategies. ${ }^{42,43}$ Engaging in shared decision-making to prioritize treatments for a given person is likely to take more time - not less - and is less amenable to standard protocol. ${ }^{4,5,41}$

Findings from this study and others ${ }^{6,44}$ suggest a role for family perspectives in the measurement of treatment burden and in discussions about prioritization of care. "Burden" associated with undertaking health care management activities has been defined as a meaningful concept to both patients ${ }^{7,14,16,44}$ and family caregivers. ${ }^{6,45}$ At times, there may be a tradeoff between these perspectives. Although health care professionals have a clear responsibility to maximize benefits and minimize harms and burden to patients who are under their care, their responsibility to involved family and close friends of patients in their care is less obvious - and in fact has been a point of longstanding debate. ${ }^{45,46}$ Some patients state a fear of being or becoming burdensome to their families as a worry that may factor in decisions. ${ }^{47}$ How to optimally balance patient and family perspectives in the measurement of constructs such as patient and family engagement, shared decision-making, or treatment burden has yet to be defined; this study highlights the importance of such work, as well as the need for evidencebased strategies that better support individuals with complex health needs as well as their family and close friends. ${ }^{4,48}$

As in any survey, results are subject to constraints of the questions that were asked, and the interpretation and validity of participant responses. Questions to assess health care decision-making preferences and treatment burden were developed based on existing literature, and were devised for broad population relevance and feasible administration within a national survey. This emphasis varies from the prevailing evidence base that has focused on decision-making preferences and experiences of care with a specific health condition, ${ }^{13,22,38}$ clinical situation, ${ }^{36,37}$ or medical encounter, ${ }^{14,28}$ although measures to ascertain these constructs are evolving. ${ }^{2,49,50}$ 
Study findings are limited to older adults' perspectives, and do not encompass perspectives of family members and close friends who may share or assume responsibility for management of health care activities. Systematic elicitation of perspectives of involved family and close friends to complement the perspectives of patients has been raised as a consideration in patient-reported outcomes and performance measurement. ${ }^{51-53}$ As individuals without the capacity to self-report their preferences and experiences with care are particularly vulnerable and susceptible to receiving contradictory, fragmented, and burdensome care, ${ }^{34,54}$ devising methods that incorporate perspectives of knowledgeable informants is necessary to a credible population-based quality measurement enterprise. More broadly, eliciting perspectives of family or close friends involved in managing health care activities ${ }^{6,9}$ and health care decision-making ${ }^{8,20,34}$ merits consideration, given they may also experience burdens associated with care. ${ }^{6,45}$

In its vision of a high performing, high value health care system, the National Quality Strategy has articulated priorities of making care safer by reducing harm, ensuring that each person and family are engaged as partners in care, and promoting effective communication and coordination of care. ${ }^{55}$ Findings from this study confirm that person-centered and family centered care is not an abstract concept, but is rather the actual context in which health care activities are managed, decisions made, and care experienced for many older adults, particularly those with more complex health needs. Our results indicate that for some, person-centered and family-centered care encompasses the active involvement of family and close friends. For others, person-centered and family-centered care may imply efforts to minimize treatment burden. Collectively, results indicate that strategies to deliver and measure person-centered and family-centered care must be flexible to respect diverse decision-making preferences, minimization of treatment burden, and support of the broader social context with which many older adults undertake health care activities.

Acknowledgements: Contributors: We gratefully acknowledge Judith Kasper for her guidance in the application of survey weights to the National Health and Aging Trends Study sampling frame, and we thank the NHATS Steering Committee for selection of the "Engagement in Health Care" supplemental module.

Funders: This study was supported by National Institute of Mental Health grant K01MH082885 (JLW) and the Paul Beeson Career Development Award Program: National Institute on Aging 1K23AG032910, AFAR, The John A. Hartford Foundation, The Atlantic Philanthropies, The Starr Foundation and an anonymous donor (CMB). The sponsor of this research was not involved in its study concept or design, recruitment of subjects or acquisition of data, data analysis or interpretation, or in the preparation of this manuscript.

\section{Prior Presentation: None}

Author's Contributions: 1) substantial contributions to conception and design (JLW and CMB), or acquisition of data (JLW), or analysis and interpretation of data (JLW and CMB; 2) drafting the article (JLW) or revising it critically for important intellectual content (JLW and CMB); and 3) final approval of the version to be published (JLW and CMB). Dr. Wolff had full access to all of the data in the study and takes responsibility for the integrity of the data and accuracy of the data analysis.

Conflict of Interest: The authors declare that they do not have a conflict of interest.

Corresponding Author: Jennifer L. Wolff, Ph.D.; Department of Health Policy and ManagementJohns Hopkins Bloomberg School of Public Health, 624 N. Broadway, Room 692, Baltimore, MD 21205, USA (e-mail: jwolff2@jhu.edu).

\section{REFERENCES}

1. Berwick DM. What 'patient-centered' should mean: confessions of an extremist. Health Aff. 2009;28:w555-w565.

2. NQF. Final report: addressing performance measure gaps in personcentered care and outcomes; 2014 August 15, 2014

3. Tinetti ME, Fried TR, Boyd CM. Designing health care for the most common chronic condition-multimorbidity. JAMA. 2012;307:2493-2494.

4. Patient-centered care for older adults with multiple chronic conditions: a stepwise approach from the american geriatrics society: american geriatrics society expert panel on the care of older adults with multimorbidity. $J$ Am Geriatr Soc. 2012;60: 1957-68.

5. Boyd C, Darer J, Boult C, Fried L, Boult L, Wu A. Clinical practice guidelines and quality of care for older patients with multiple comorbid diseases: implications for pay for performance. JAMA. 2005;294:716-724.

6. Giovannetti ER, Wolff $\mathbf{J L}$, Xue $\mathbf{Q} \mathbf{L}$, et al. Difficulty assisting with health care tasks among caregivers of multimorbid older adults. J Gen Intern Med. 2011.

7. Boyd C, Wolff J, Giovannetti E, et al. Health care task difficulty among older adults with multimorbidity. Med Care. 2014;52:S118-S125.

8. Wolff J, Roter D. Family presence in routine medical visits: a metaanalytical review. Soc Sci Med. 2011;72:823-831.

9. IOM. Retooling for an aging America: building the health care workforce. Washington, DC: The National Academies Press; 2008.

10. Levinson W, Kao A, Kuby A, Thisted R. Not all patients want to participate in decision making. A national study of public preferences. $J$ Gen Intern Med. 2005;20:531-535.

11. Zikmund-Fisher B, Couper M, Singer E, et al. The DECISIONS study: a nationwide survey of United States adults regarding 9 common medical decisions. Med Decis Making. 2010;30:20S-34S.

12. Naik AD, Street RL, Jr., Castillo D, Abraham NS. Health literacy and decision making styles for complex antithrombotic therapy among older multimorbid adults. Patient Educ Couns. 2011.

13. Gallacher K, Morrison D, Jani B, et al. Uncovering treatment burden as a key concept for stroke care: a systematic review of qualitative research. PLoS Med. 2013; 10:e1001473.

14. Eton DT, Elraiyah TA, Yost KJ, et al. A systematic review of patientreported measures of burden of treatment in three chronic diseases. Patient Relat Outcome Meas. 2013;4:7-20.

15. Elkin EB, Kim SH, Casper ES, Kissane DW, Schrag D. Desire for information and involvement in treatment decisions: elderly cancer patients' preferences and their physicians' perceptions. J Clin Oncol Off $\mathrm{J}$ Am Soc Clin Oncol. 2007;25:5275-5280.

16. Gallacher KI, Montori VM, May CR, Mair FS. Chapter 8: treatment burden and multimorbidity. In: Mercer SW, Salisbury C, Fortin M, eds. ABC of Multimorbidity. Hoboken: Wiley; 2014.

17. Kasper JD, Freedman VA. National health and aging trends study user guide: rounds $1 \& 2$, beta release. Baltimore: Johns Hopkins University School of Public Health; 2013.

18. Montaquila J, Freedman VA, Edwards B, Kasper JD. National Health and Aging Trends Study (NHATS) Round 1 Sample Design and Selection. Baltimore: Johns Hopkins University School of Public Health; 2012. 
19. Montaquila J, Freedman VA, Spillman BC, Kasper JD. National health and aging trends study technical paper \#6: development of round 2 survey weights. Baltimore: Johns Hopkins University School of Public Health; 2014.

20. Price EL, Bereknyei S, Kuby A, Levinson W, Braddock CH 3rd. New elements for informed decision making: a qualitative study of older adults' views. Patient Educ Couns. 2012;86:335-341.

21. Legare F, Stacey D, Pouliot $\mathbf{S}$, et al. Interprofessionalism and shared decision-making in primary care: a stepwise approach towards a new model. J Interprof Care. 2011;25:18-25.

22. Vijan S, Hayward R, Ronis D, Hofer T. Brief report: the burden of diabetes therapy: implications for the design of effective patient-centered treatment regimens. J Gen Intern Med. 2005;20:479-482.

23. Townsend A, Hunt $\mathbf{K}$, Wyke $\mathbf{S}$. Managing multiple morbidity in mid-life: a qualitative study of attitudes to drug use. BMJ. 2003;327:837.

24. Bayliss E, Ellis J, Steiner J. Seniors' self-reported multimorbidity captured biopsychosocial factors not incorporated into two other databased morbidity measures. J Clin Epidemiol. 2008.

25. Kroenke K, Spitzer R, Williams J. The patient health questionnaire-2: validity of a two-item depression screener. Med Care. 2003;41:1284-1292.

26. Galvin JE, Roe CM, Xiong C, Morris JC. Validity and reliability of the AD8 informant interview in dementia. Neurology. 2006;67:1942-1948.

27. Kasper J, Freedman V, Spillman B. Classification of Persons by Dementia Status in the National Health and Aging Trends Study: Technical Paper \#5. Baltimore: Johns Hopkins University School of Public Health; 2013.

28. Chewning B, Bylund CL, Shah B, Arora NK, Gueguen JA, Makoul G. Patient preferences for shared decisions: a systematic review. Patient Educ Couns. 2012;86:9-18.

29. Bastiaens H, Van Royen P, Pavlic DR, Raposo V, Baker R. Older people's preferences for involvement in their own care: a qualitative study in primary health care in 11 European countries. Patient Educ Couns. 2007;68:33-42.

30. Belcher V, Fried T, Agostini J, Tinetti M. Views of older adults on patient participation in medication-related decision making. $\mathrm{J}$ Gen Intern Med. 2006;21:298-303.

31. Morton R, Tong A, Howard $\mathbf{K}$, Snelling $\mathbf{P}$, Webster A. The views of patients and carers in treatment decision making for chronic kidney disease: systematic review and thematic synthesis of qualitative studies. BMJ. 2010;340:c112

32. Smith SK, Dixon A, Trevena L, Nutbeam D, McCaffery KJ. Exploring patient involvement in healthcare decision making across different education and functional health literacy groups. Soc Sci Med. 2009;69:1805-1812.

33. Ho A. Relational autonomy or undue pressure? Family's role in medical decision-making. Scand J Caring Sci. 2008;22:128-135.

34. Torke AM, Sachs GA, Helft PR, et al. Scope and outcomes of surrogate decision making among hospitalized older adults. JAMA Intern Med. 2014.

35. Levine C, Halper D, Rutberg J, Gould DA. Engaging family caregivers as partners in transitions. New York, NY: United Hospital Fund; 2013.

36. Walter LC, Eng C, Covinsky KE. Screening mammography for frail older women: what are the burdens? J Gen Intern Med. 2001;16:779-784.

37. Fried TR, Bradley EH, Towle VR, Allore H. Understanding the treatment preferences of seriously ill patients. N Engl J Med. 2002;346:1061-1066.
38. Gallacher K, May CR, Montori VM, Mair FS. Understanding patients' experiences of treatment burden in chronic heart failure using normalization process theory. Ann Fam Med. 2011;9:235-243.

39. Montori VM, Brito JP, Murad MH. The optimal practice of evidence-based medicine: incorporating patient preferences in practice guidelines. JAMA. 2013;310:2503-2504.

40. May C, Montori VM, Mair FS. We need minimally disruptive medicine. BMJ. 2009;339:b2803.

41. Reuben DB, Tinetti ME. Goal-oriented patient care-an alternative health outcomes paradigm. N Engl J Med. 2012;366:777-779.

42. Yarnall KS, Pollak KI, Ostbye T, Krause KM, Michener JL. Primary care: is there enough time for prevention? Am J Public Health. 2003:93:635-641.

43. Ostbye T, Yarnall KS, Krause KM, Pollak KI, Gradison M, Michener JL. Is there time for management of patients with chronic diseases in primary care? Ann Fam Med. 2005;3:209-214.

44. Tran VT, Montori VM, Eton DT, Baruch D, Falissard B, Ravaud P. Development and description of measurement properties of an instrument to assess treatment burden among patients with multiple chronic conditions. BMC Med. 2012;10:68.

45. Adelman RD, Tmanova LL, Delgado D, Dion S, Lachs MS. Caregiver burden: a clinical review. JAMA. 2014;311:1052-1060.

46. Physicians and family caregivers. A model for partnership. Council on Scientific Affairs, American Medical Association. JAMA J Am Med Assoc. 1993;269:1282-4.

47. Cahill E, Lewis L, Barg F, Bogner H. "You don't want to burden them": older adults' views on family involvement in care. J Fam Nurs. 2009;15:295-317.

48. Kelly K, Reinhard S, Brooks-Danso A. Professional partners supporting family caregivers. Am J Nurs. 2008;108:6-12.

49. Mair FS, May CR. Thinking about the burden of treatment. BMJ. 2014;349:g6680.

50. Tran VT, Harrington M, Montori VM, Barnes C, Wicks $\mathbf{P}$, Ravaud $\mathbf{P}$. Adaptation and validation of the Treatment Burden Questionnaire (TBQ) in English using an internet platform. BMC Med. 2014;12:109.

51. Cella D, Hahn EA, Jensen SE, Butt Z, Nowinski CJ, N. R. Methodological issues in the selection, administration, and use of patient-reported outcomes in performance measurement in health care settings. Retrieved from http://www.qualityforum.org/Projects/n-r/Patient-Reported_Outcomes /

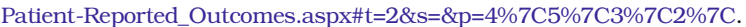

52. Deutsch A, Smith L, Gage B, Kelleher C, Garfinkel D. Patient-reported outcomes in performance measurement: commissioned paper on PRObased performance measures for healthcare accountable entities: prepared for the national quality forum; 2012 October 22, 2012.

53. Giovannetti ER, Reider $\mathbf{L}$, Wolff $\mathbf{J L}$, et al. Do older patients and their family caregivers agree about the quality of chronic illness care? Int $\mathrm{J}$ Qual Health Care J Int Soc Qual Health Care / ISQua. 2013;25:515-524.

54. Mitchell SL, Teno JM, Kiely DK, et al. The clinical course of advanced dementia. N Engl J Med. 2009;361:1529-1538.

55. Working for quality: 2013 Annual progress report to Congress: National Strategy for Quality Improvement in Health Care. 2013. (Accessed 3/13/ 2015, at http://www.ahrq.gov/workingforquality/.) 